\section{Barriers to Intersubgeneric Crosses between Muscadinia and Euvitis}

\author{
Jiang L $\mathbf{u}^{1}$ and Olusola Lamikanra ${ }^{2}$ \\ Center for Viticultural Science, Florida A\&M University, Tallahassee, \\ FL 32310
}

Additional index words. Vitis, grape, style, pollen tube, genetic incongruity, fluorescence microscopy, interspecific hybridization

\begin{abstract}
Fluorescence microscopy was used to examine the unilateral intersubgeneric incongruity of muscadine grape (Muscadinia Planch.) $x$ bunch grape (Euvitis Planch.). Pollen grains of bunch grape hydrated and germinated on the stigmas of muscadine grape. Healthy pollen tubes of the bunch grape also penetrated the stigma and entered into the style without obstacles. However, most bunch grape pollen tubes were arrested in the style near the stigma, and few bunch grape pollen tubes were found at the base of the style. Barriers to the intersubgeneric crosses apparently occurred before fertilization; abortion of pollen tubes in the style was the major cause of failure for the cross of $V$. rotundifolia Michx. x Euvitis.
\end{abstract}

Wild and cultivated grapevines belong to the genus Vitis L. in the family Vitaceae Planch. The genus Vitis is divided into two subgenera: Euvitis Planch. and Muscadinia Planch. (Olien, 1990; Winkler et al., 1974). The former has 38 chromosomes and many berries borne in each cluster, so the general term "bunch grape" is given to the subgenus Euvitis. The latter has 40 chromosomes and smaller clusters, with a common name of muscadine grape. More than 60 species have been described in Euvitis, and $V$. vinifera $\mathrm{L}$. is the predominant commercial species cultivated worldwide (Alleweldt et al., 1991; Zhang et al., 1990). Only three species (V. rotundifolia Michx., $V$. munsoniana Simpson ex Munson, and $V$. popenoei Fennell) have been identified in the subgenus Muscadinia. Vitis rotundifolia, normally referred to as the muscadine grape, is the only species with commercial value.

Vitis rotundifolia is native to the southeastern United States and is characterized by high disease, insect, and nematode resistance. It has resistance to most fungal diseases and Pierce's disease (PD), caused by the bacterium Xylella fastidiosa Wells (Olmo, 1971), a limiting factor in the production of $V$. vinifera grapes in the southeastern United States. Except for a few species native to the southeastern United States, bunch grapes are susceptible to these pests but have positive characteristics, such as a large cluster, edible skin and pulp, and

Received for publication 11 Apr. 1995. Accepted for publication 15 Nov. 1995. We thank D.W. Ramming, U.S. Dept. of Agriculture (USDA), Fresno, Calif., for providing the pollen grains of 'Thompson Seedless' and 'Flame Seedless' and L. Schell for providing technical assistance. This work was supported in part by USDA grant 91-38814-6235. The cost of publishing this paper was defrayed in part by the payment of page charges. Under postal regulations, this paper therefore must be hereby marked advertisement solely to indicate this fact.

${ }^{1}$ Assistant Professor, Geneticist, and Breeder.

${ }^{2}$ Professor and Director at the Center for Viticultural

Sciences, Florida A\&M Univ., Tallahassee. seedlessness, which have not been found in muscadine grapes. Hybridization of these two grapes to obtain bunch grape fruit quality and good disease resistance from $V$. rotundifolia has been a long-term goal for grape breeders.

Intersubgeneric crosses between muscadine and bunch grapes have been performed for more than a century by breeders in several grape breeding programs (Bouquet, 1981; Detjen, 1919; Dunstan, 1962; Olmo, 1971, 1986). Vitis rotundifolia will hybridize quite readily with some species of Euvitis when used as the male parent, but when used as the female parent, it will hybridize only rarely.

The failure to produce hybrids from the muscadine stigma pollinated with bunch grape
${ }^{\mathrm{z}}$ Numbers were combined from all five collection-time treatments. pollen in various attempts over a century clearly indicates that a unilateral incompatibility exists between the Muscadinia $\times$ Euvitis crosses. Based on a histochemical study, Patel and Olmo (1955) concluded that the reason for the complete failure of rotundifolia $\mathrm{x}$ vinifera crosses was not due to failure of pollen tube growth but to barriers in the embryo sac. Since interspecific incongruity may vary depending on the species that are crossed, we determined whether the inconcruity described by Patel and Olmo also appears in crosses of $V$. rotundifolia pollinated by pollen of other Vitis species. In addition, we used fluorescence microscopy to determine more efficiently the distance pollen tubes penetrate in grape. Fluorescence staining and squashing technique also can trace pollen tube growth from stigmas to ovules.

\section{Materials and Methods}

Twenty-four, cross combinations were used for this study (Table 1). Sixteen of them were $V$. rotundifolia $\times$ Euvitis, including four female muscadine parents ('Fry', 'Higgins', 'Jumbo', 'Summit') and four bunch grape pollen parents ('Thompson Seedless', 'Flame Seedless', 'Orlando Seedless', and 'Blanc du Bois'). Four combinations of Euvitis $\mathrm{x} V$. rotundifolia and four combinations of $V$. rotundifolia $\times V$. rotundifolia were used as control crosses. The muscadine grapes, 'Orlando Seedless', and 'Blanc du Bois' were grown in the experimental vineyard at Florida A\&M Univ., while fresh pollen of 'Thompson Seedless' and 'Flame Seedless' was obtained from the Horticultural Crops Research Laboratory, U.S. Dept. of Agriculture, Agricultural Research Service, Fresno, Calif.

Table 1. Pollen tube growth in inter- and intraspecific crosses of muscadine and bunch grapes.

\begin{tabular}{|c|c|c|c|c|c|}
\hline \multirow[b]{3}{*}{ Crosses } & \multirow{3}{*}{$\begin{array}{c}\text { Pistils } \\
\text { examined }^{\mathrm{z}}\end{array}$} & \multicolumn{4}{|c|}{ Pistils with pollen tubes } \\
\hline & & \multicolumn{2}{|c|}{ Near stigma } & \multicolumn{2}{|c|}{ At base of style } \\
\hline & & No. & $\%$ & $\overline{\text { No. }}$ & $\%$ \\
\hline \multicolumn{6}{|l|}{ Vitis rotundifolia $\times$ Euvitis } \\
\hline Fry $x$ Flame Seedless & 25 & 17 & 68.0 & 0 & 0 \\
\hline Fry $x$ Thompson Seedless & 25 & 20 & 80.0 & 2 & 8.0 \\
\hline Fry x Orlando Seedless & 24 & 14 & 58.3 & 4 & 16.7 \\
\hline Fry $x$ Blanc du Bois & 23 & 18 & 78.3 & 1 & 4.3 \\
\hline Higgins $x$ Flame Seedless & 25 & 20 & 80.0 & 0 & 0 \\
\hline Higgins $x$ Thompson Seedless & 25 & 14 & 56.0 & 0 & 0 \\
\hline Higgins $x$ Orlando Seedless & 25 & 20 & 80.0 & 3 & 12.0 \\
\hline Higgins $x$ Blanc du Bois & 25 & 15 & 60.0 & 2 & 8.0 \\
\hline Jumbo x Flame Seedless & 24 & 18 & 75.0 & 0 & 0 \\
\hline Jumbo $\times$ Thompson Seedless & 25 & 15 & 60.0 & 3 & 12.0 \\
\hline Jumbo x Orlando Seedless & 20 & 11 & 55.0 & 0 & 0 \\
\hline Jumbo $x$ Blanc du Bois & 20 & 11 & 55.0 & 1 & 5.0 \\
\hline Summit x Flame Seedless & 25 & 14 & 70.0 & 0 & 0 \\
\hline Summit $\times$ Thompson Seedless & 23 & 21 & 91.3 & 1 & 4.3 \\
\hline Summit x Orlando Seedless & 25 & 17 & 68.0 & 0 & 0 \\
\hline Summit $x$ Blanc du Bois & 22 & 11 & 50.0 & 2 & 9.1 \\
\hline \multicolumn{6}{|l|}{ Euvitis $\times$ V. rotundifolia } \\
\hline Blanc du Bois $\times$ Carlos & 23 & 14 & 60.9 & 13 & 56.5 \\
\hline Blanc du Bois $\times$ Noble & 22 & 12 & 54.5 & 10 & 45.5 \\
\hline Orlando Seedless $\times$ Carlos & 21 & 13 & 61.9 & 11 & 52.3 \\
\hline Orlando Seedless $\times$ Noble & 22 & 9 & 40.9 & 9 & 40.9 \\
\hline \multicolumn{6}{|l|}{$V$. rotundifolia $\times$ V. rotundifolia } \\
\hline Fry $x$ Carlos & 25 & 21 & 84.0 & 21 & 84.0 \\
\hline Fry $x$ Noble & 25 & 18 & 72.0 & 16 & 64.0 \\
\hline Jumbo x Carlos & 25 & 24 & 96.0 & 24 & 96.0 \\
\hline Jumbo $\times$ Noble & 25 & 23 & 92.0 & 23 & 92.0 \\
\hline
\end{tabular}




\section{Breeding, Cultivars, Rootstocks, \& Germplasm Resources}

'Orlando Seedless' and 'Blanc du Bois' were emasculated 1 day before anthesis, and paper bags were used to cover the flower clusters immediately thereafter. No emasculation was needed for the muscadine cultivars Fry, Higgins, Jumbo, and Summit since they produce pistillate flowers. Instead, paper bags were used to cover the flower clusters several days before pollination. Pollination was performed in the morning between 8:00 AM and 10:00 AM. A glass rod carrying pollen grains was gently touched onto the stigma surface. Five to 10 clusters of flowers, with a total of $\geq 250$ flowers, were pollinated for each cross combination. Five pollinated flowers for each cross were collected $8 \mathrm{~h}, 1$ day, 2 days, 3 days, and 5 days after pollination and were fixed in 1 formalin : 1 acetic acid : 8 alcohol. The fixed pistils were stored in a refrigerator at $4 \mathrm{C}$ until microscopic examination. The remaining flowers were left on the vines for further observation.

The pistils were cleared and softened in 1 $\mathrm{N} \mathrm{NaOH}$ for $2 \mathrm{~h}$ at $25 \mathrm{C}$, then moved to a $60 \mathrm{C}$ water bath for $45 \mathrm{~min}$, and stained with $0.1 \%$ aniline blue in $0.1 \mathrm{~N} \mathrm{~K}_{3} \mathrm{PO}_{4}$ for $2 \mathrm{~h}$. The pistils were squashed under a cover slip and were examined under a fluorescent microscope.

\section{Results and Discussion}

The aniline blue staining technique worked fairly well for staining grape pollen tubes, as they were distinguished clearly from the surrounding stylar tissue by the presence of a strong fluorescence (Fig. 1). In these intraspecific crosses, pollen tubes appeared healthy and grew all the way to the base of the style. For example, $>90 \%$ of the examined pistils of 'Jumbo' $x$ 'Carlos' and 'Jumbo' $x$ 'Noble' had pollen tubes at the base of the style (Table 1). The pollen tubes were found at the base of the style as early as $8 \mathrm{~h}$ after pollination. By using the fluorescence microscopy staining technique, we could examine pollen tubes on the same day that the pistils were excised from the vine. The simplicity and quickness of the fluorescence microscopy staining technique encouraged us to use it to study pollen tube growth in intersubgeneric crosses.

As with the intraspecific crosses of $V$. rotundifolia, the pollen grains of muscadine grapes germinated on the stigmas of the Euvitis 'Orlando Seedless' and 'Blanc du Bois'. Pollen tubes also penetrated the stigma without obstacles. Healthy pollen tubes were found at the base of the Euvitis styles from 8 to $24 \mathrm{~h}$ after pollination. In the $V$. rotundifolia $\times$ Euvitis crosses, the Euvitis pollen grains also germinated on the muscadine stigmas. The pollen tubes that entered the stigma and penetrated the style were similar to those of Euvitis $\times V$. rotundifolia. However, unlike the crosses of Euvitis $\times$ V. rotundifolia, most of the bunch grape pollen tubes were arrested in the style near the stigma end of the muscadine grapes (Fig. 2). Only occasionally were one or two pollen tubes of the bunch grapes at the base of the $V$. rotundifolia styles (Fig. 3, Table 1). This phenomenon appeared in all of the $V$. rotundifolia $\mathrm{x}$ Euvitis crosses in this study.

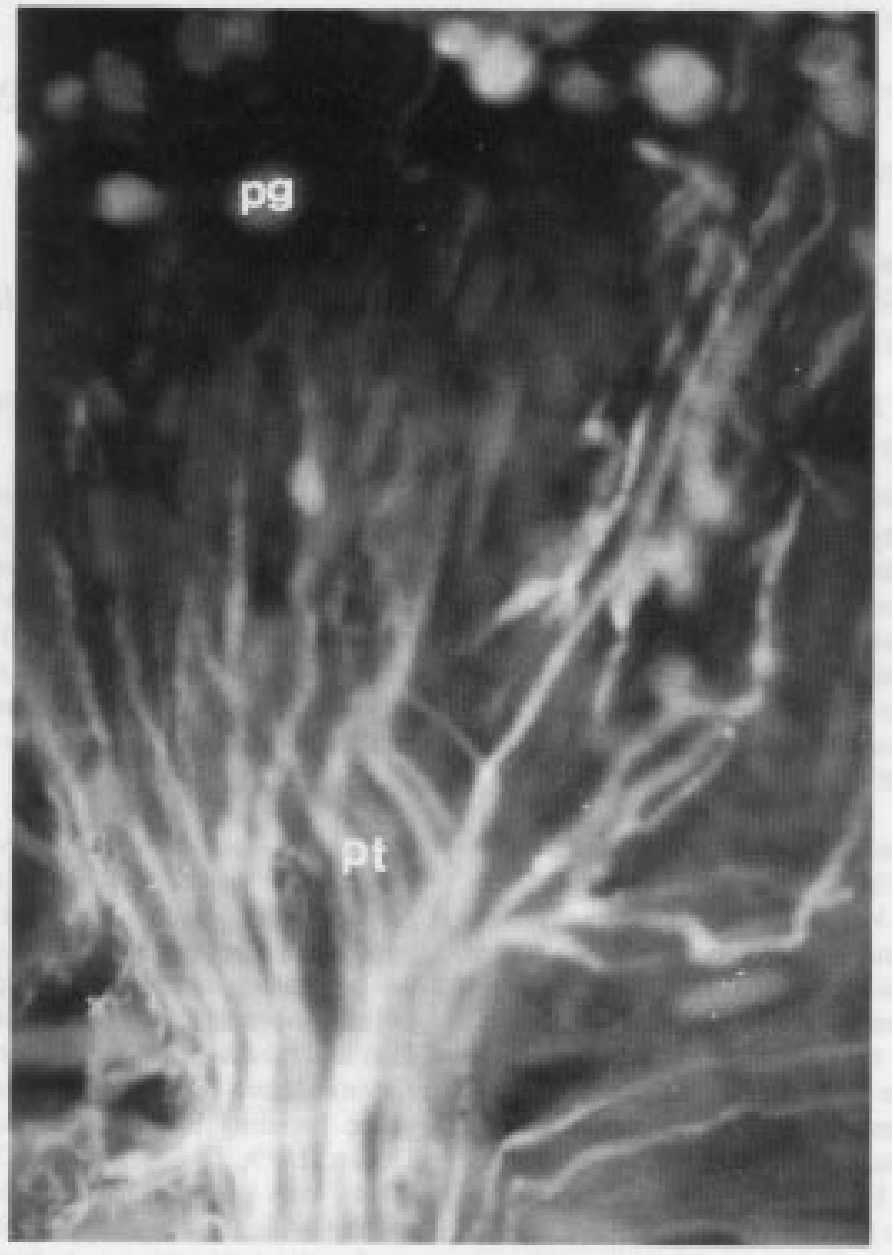

Fig. 1. Fluorescence micrograpn or tne squasnea pistu or fry muscauıne grape $\angle 4 \mathrm{n}$ anter pollination with pollen of 'Carlos' muscadine grape; $p g=$ pollen grain and $\mathrm{pt}=$ pollen tube, $\times 200$.

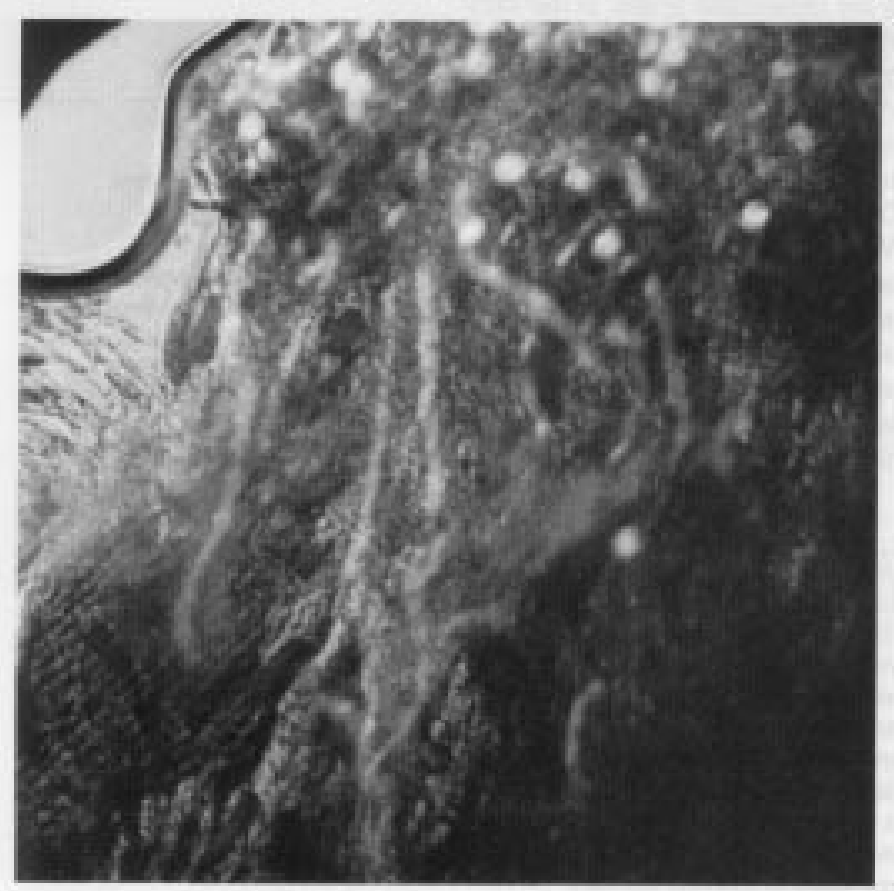

Fig. 2. Arrest of pollen tubes in the style near the stigma in the intersubgeneric cross of 'Fry' $x$ 'Orlando Seedless' $48 \mathrm{~h}$ after pollination; $\times 100$. 


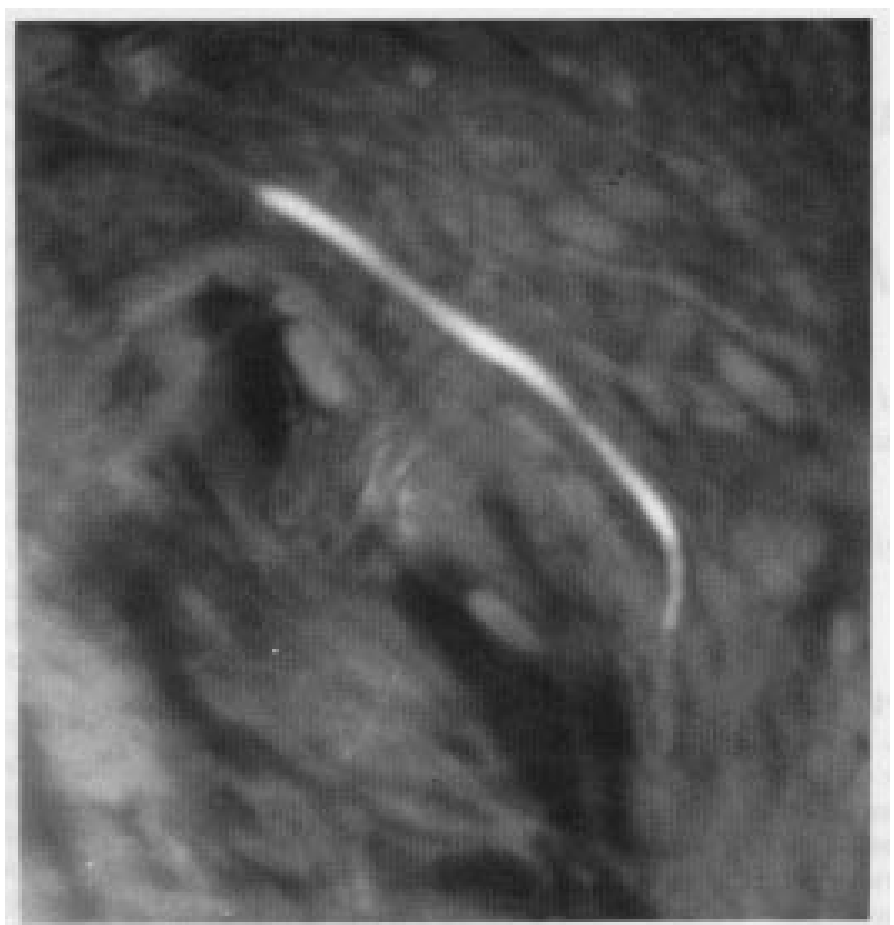

Fig. 3. A single pollen tube aborted at the base of the style in the intersubgeneric cross of 'Fry' $x$ 'Blanc du Bois' $48 \mathrm{~h}$ after pollination; $\times 220$.

When 'Flame Seedless' was used as a pollen parent, none of the pollen tubes grew all the way down the style, while in all four crosses of $V$. rotundifolia $x$ 'Blanc du Bois', at least one pollen tube reached the base of the style. However, it is difficult to interpret such a difference into genotype variation since the percentage of styles with pollen tubes reaching to the stylar base was so low. When a comparison was made at the species level (vinifera vs. the American hybrids), no significant difference was found whether $V$. vinifera ('Flame Seedless', 'Thompson Seedless') or American hybrid bunch grapes ('Orlando Seedless', 'Blanc du Bois') were used as the pollen parents $\left(\chi^{2}=3.2,1 \mathrm{df}\right)$.

Among flowers that had been left on the vines, only one hybrid was obtained from a cross of 'Jumbo' $x$ 'Thompson Seedless' among the 16 cross combinations of $V$. rotundifolia $\times$ Euvitis.

As part of our breeding program in 1993, pollen of the stenospermocarpic grapes used in the intersubgeneric crosses also were put onto stigmas of Euvitis grape 'Blanc du Bois' ('Blanc du Bois' X 'Orlando Seedless', 'Blanc du Bois' x 'Flame Seedless', and 'Blanc du Bois' $x$ 'Thompson Seedless'). Hundreds of $F_{1}$ hybrids were produced from these crosses (data not shown). This result implies that the pollen grains used in the intersubgeneric crosses were viable and vigorous, and the abnormality of pollen tube growth in the style of $V$. rotundifolia was not caused by defective pollen.

In angiosperms, many events occur between pollen germination and seed production, such as pollen hydration and germination, pollen tube penetration through the stigma surface, pollen tube growth in the style, and fertilization and embryo development (Williams, 1987). Barriers to any of these series of events can lead to the failure of seed formation. The pollen tube abortion in the styles of $V$. rotundifolia appeared to be the major cause of failure in the muscadine $x$ bunch grapes crosses. This conclusion differed from the one of Patel and Olmo (1955) — that the reason for complete failure of crossing rotundifolia $\mathrm{x}$ vinifera was due to the barrier in the embryo sac but not due to the failure of pollen tube growth. A possible reason for this difference may be that they used genotypes that differed from ours. However, the reoccurrence of the pollen tube being aborted in the style for all the muscadine $x$ bunch crosses implies that pollen tube abortion in the style is a common phenomenon in $V$. rotundifolia $x$ Euvitis. Since few pollen tubes were at the base of some styles but only one hybrid was developed among the 16 cross combinations from $>3000$ pollinated flowers left on the vines, barriers also may exist somewhere between the base of the style and the embryo sac. The latter con- clusion is similar to the findings of Patel and Olmo (1955), but it implies a second barrier site in addition to the one in the style. Embryo rescue may help to recover hybrids if the failure of seed set results from embryo abortion, which is common in many wide crosses. However, our results show that this is not a possibility since the incompatibility of muscadine $\mathrm{x}$ bunch grapes took place before fertilization. Overcoming the prefertilization barriers, therefore, must be the first step in obtaining hybrids when muscadine is used as the female parent. Further research is warranted to see if techniques (such as bud pollination, style pollination, application of gibberellic acid, etc.) can be used to overcome prefertilization barriers. However, the low fruit set in Euvitis $\times$ V. rotundifolia crosses may be due, in part, to postfertilization barriers since no stylar barrier was observed in those crosses. This prediction is in agreement with the report of Goldy et al. (1989), who found that success could be enhanced if hybrid embryos were rescued 6 weeks after pollination.

\section{Literature Cited}

Alleweldt, G., P. Spiegel-Roy, and B.I. Reigh. 1991. Grapes(Vitis). In: J.N. Moore and J.R. Ballington, Jr. (eds.). Genetic resources of temperate fruit and nut crops. Acta Hort. 290:291-337.

Bouquet, A. 1981. Vitis x Muscadinia hybridization: A new way in grape breeding for disease resistance in France. Proc. 3rd Intl. Symp. Grape Breeding, 1980. Univ. of California, Davis. p. $42-61$.

Detjen, L.R. 1919. Some $F_{1}$ hybrids of $V$. rotundifolia with related species and genera. North Carolina Agr. Expt. Sta. Technol. Bul. 18:1-50.

Dunstan, R.T. 1962. Some fertile hybrids of bunch and muscadine grapes. J. Hered. 53:299-303.

Goldy, R.G., D.W. Ramming, R.L. Emershad, and J.X. Chaparro. 1989. Increasing production of Vitis vinifera $\times V$. rotundifolia hybrids through embryo rescue. HortScience 24:820-822.

Olien, W.C. 1990. The muscadine grape: Botany, viticulture, history, and current industry. HortScience 25:732-739.

Olmo, H.P. 1971. Vinifera $\mathrm{x}$ rotundifolia hybrids as wine grapes. Amer. J. Enol. Viticult. 22:87-91.

Olmo, H.P. 1986. The potential role of (vinifera $\mathrm{X}$ rotundifolia) hybrids in grape variety improvements. Experientia 42:921-926.

Patel, G.I. and H.P. Olmo. 1955. Cytogenetics of Vitis: 1 . The hybrid $V$. vinifera $\times V$. rotundifolia. Amer. J. Bot. 42:141-159.

Williams, E.G. 1987. Interspecific hybridization in pasture legumes. Plant Breeding Rev. 5:237306.

Winkler, A.J., J.A. Cook, W.M. Kliewer, and L.A. Lider. 1974. General Viticulture. 2nd ed. Univ. of California Press, Berkeley.

Zhang, F., F. Luo, and D. Gu. 1990. Studies on germplasm resources of wild grape species (Vitis spp). Proc. 5th Intl. Symp. Grape Breeding, 1989. St. Martin/Pfalz, Germany. p. 50-57. 